\title{
Association of Spontaneous and Induced Self-Affirmation With Smoking Cessation in Users of a Mobile App: Randomized Controlled Trial
}

Elizabeth L Seaman ${ }^{1}$, MHS, PhD; Cendrine D Robinson ${ }^{2}, \mathrm{MPH}, \mathrm{PhD}$; David Crane ${ }^{3}, \mathrm{PhD}$; Jennifer M Taber ${ }^{4}, \mathrm{PhD}$; Rebecca A Ferrer ${ }^{2}, \mathrm{PhD}$; Peter R Harris ${ }^{5}$, PhD; William M P Klein ${ }^{2}, \mathrm{PhD}$

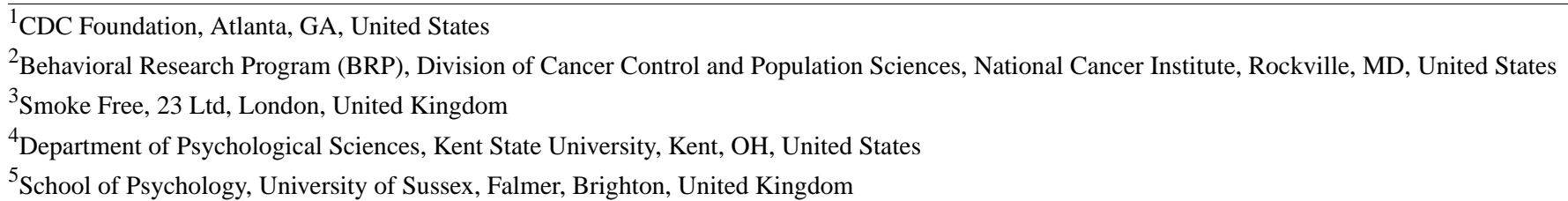

\section{Corresponding Author:}

Elizabeth L Seaman, MHS, PhD

CDC Foundation

600 Peachtree Street NE, Suite 1000

Atlanta, GA, 30308

United States

Phone: 14438524139

Email: eseaman@cdcfoundation.org

\begin{abstract}
Background: Most smokers attempt to stop using cigarettes numerous times before successfully quitting. Cigarette cravings may undermine perceived competence to quit and thus constitute psychological threats to the individual's self-concept. Self-affirmation may promote smoking cessation by offsetting these threats.

Objective: This study examines whether self-affirmation is associated with smoking cessation in the context of a cessation app. Two types of self-affirmation are examined: tendency to spontaneously self-affirm, and self-affirmation inductions added to a publicly available smoking cessation app (Smoke-Free Quit Smoking Now). In addition, this study explores whether optimism and emotional states (happiness, anger, anxiousness, hopefulness, sadness) predict smoking cessation.

Methods: All users who met the inclusion criteria, provided consent to participate, and completed a baseline assessment, including all individual difference measures, were randomized to 1 of 4 conditions. Half of the participants were randomly assigned to complete a self-affirmation induction upon study entry. Orthogonally, half of the participants were randomly assigned to receive self-affirming text notifications during their quit attempt or to receive conventional notifications. The induction and the text notifications were fully automated, and all data were collected through self-assessments in the app. Self-reported smoking cessation was assessed 1 month and 3 months following study entry.
\end{abstract}

Results: The study enrolled 7899 participants; 647 completed the 1-month follow-up. Using an intent-to-treat analysis at the 1-month follow-up, 7.2\% (569/7899) of participants self-reported not smoking in the previous week and 6.4\% (503/7899) self-reported not smoking in the previous month. Greater tendency to spontaneously self-affirm predicted a greater likelihood of cessation $(P<.001)$ at 1 month after controlling for smoking-related variables. Neither self-affirmation induction influenced cessation. In addition, spontaneous self-affirmation did not moderate the relationship between self-affirmation inductions and cessation. Greater baseline sadness was associated with a lower likelihood of reporting successful cessation. Optimism predicted past-week cessation at the 1-month follow-up, and both happiness and anger predicted past-month cessation at the 1-month follow-up; however, none of these potential predictors moderated the relationship between self-affirmation conditions and successful cessation.

Conclusions: Spontaneous self-affirmation may be an important psychological resource for managing threats to self-concept during the smoking cessation process. Sadness may hinder quit attempts. Future research can explicate how spontaneous versus induced self-affirmation can promote smoking cessation and examine boundary conditions for the effectiveness of disseminated self-affirmation interventions. 
Trial Registration: ISRCTN Registry 56646695; https://www.isrctn.com/ISRCTN56646695

(J Med Internet Res 2021;23(3):e18433) doi: $\underline{10.2196 / 18433}$

\section{KEYWORDS}

smoking cessation; smartphone; mHealth; sadness; self-affirmation; spontaneous self-affirmation; apps; mobile phone

\section{Introduction}

\section{Background}

Tobacco use remains a leading cause of preventable death and disease globally, contributing to over 7.1 million deaths annually [1]. Each year, approximately 343,000 people in the United States die from cancer related to tobacco use [2]. Many adults are motivated to quit smoking cigarettes; however, most attempts to quit are unsuccessful $[3,4]$. Clinical practice guidelines emphasize combining pharmacological treatments with behavioral interventions [5]. There are several empirically supported behavioral treatments for smoking cessation [6]. However, the high rate of unsuccessful quit attempts [7] suggests that there is a need for supplementary and easily disseminable behavioral interventions.

\section{Mobile Health and Smoking Cessation}

There is a growing body of literature supporting behavioral smoking cessation treatments delivered via mobile health platforms, including smartphones [8-10]. As smartphone access in the United States continues to rise, more individuals will have access to behavioral interventions delivered on smartphones. About $81 \%$ of US adults own a smartphone [11], and $72 \%$ of adult internet users have searched for health-related information on the web [12]. One international systematic review established that web-based health information seeking is common in many different countries and found that web-based health information seeking can improve patient-physician relationships [13].

Smartphone apps for smoking cessation can include a variety of theory-based intervention components that promote cessation, such as techniques to facilitate coping with craving and behavioral strategies for removing smoking-related stimuli from a smoker's house [14]. Smoke Free-Quit Smoking Now is one such mobile app for smoking cessation that includes the behavior change techniques of supporting users to take on the identity of a nonsmoker, rewarding cessation, and changing routines [15].

\section{Self-Affirmation Theory and Applications to Smoking Cessation}

Quitting smoking is a difficult endeavor, and most smokers attempt cessation many times before they successfully quit [16]. The process of attempting to quit smoking may in itself be psychologically threatening, as smokers may interpret cravings and temporary relapse during the process as indicators of lack of competence for quitting, constituting a threat to self-concept that results in negative affect [17]. When self-competence is threatened, it may undermine the cessation process by reducing motivation to quit or cessation self-efficacy. Many smoking cessation interventions bolster perceived competence to quit
[18]. However, interventions to protect the self-concept are less common and may bolster the effectiveness of existing cessation interventions.

One such intervention approach is based on self-affirmation theory. According to this theory, people are highly motivated to see themselves as having self-integrity, which is marked by a sense of moral adequacy and competence [19]. Thus, when they experience threats to these attributes, they may respond defensively in an attempt to protect and bolster their self-integrity [20,21]. Health behavior change interventions often contain such threats because they suggest that one is volitionally engaged in a behavior that is harmful or irrational [22,23]. Defensiveness in the face of threats to self-integrity has been observed among smokers [24,25]. For example, smokers may respond to threatening cessation messages by impugning their content [26]. Even smoking cessation materials that are not explicitly threatening or loss-framed may be perceived as threatening by smokers attempting to quit or former smokers struggling with relapse. Self-affirmation theory suggests that to the extent that people can sustain views of themselves as morally adequate and competent, they will be more open to specific threats to the self. For example, smokers who are reassured about their self-integrity may be able to better face the challenges of cessation [27]. Accordingly, much research shows that when people have an opportunity to reflect on, for example, their cherished values before being exposed to threatening health information, such as a graphic warning label [24,28] or personal disease risk [29], they are more receptive to that information and may be more likely to engage in risk reduction behavior (meta-analyses [30-32]). We thus hypothesized that self-affirmation could offset the potential threats associated with quitting and, in turn, promote successful cessation.

Although evidence suggests that self-affirmation inductions can improve engagement with and efficacy of health behavior intentions, evidence is mixed for studies specifically targeting smokers. Some studies have found benefits of self-affirmation [28,33-38], including less defensiveness toward graphic warnings [28,36]. Moreover, when combined with other intervention strategies, such as motivational interviewing and cessation programs, self-affirmed individuals reduced cigarette consumption [37]. However, other studies have not found beneficial effects of self-affirmation on smoking-related outcomes for daily smokers $[35,39,40]$. Thus, additional research is needed to determine the effectiveness of induced self-affirmations among smokers.

In addition to research on self-affirmation inductions, some people are more likely than others to naturally or spontaneously engage in self-affirmation when feeling threatened or anxious [34,41-43]. Spontaneous self-affirmation may serve as a resource to facilitate smoking cessation because of its potential to offset 
cessation-related psychological threats in ways similar to induced self-affirmation. Indeed, the tendency to report spontaneous self-affirmation has been associated with greater acceptance of threatening health information [41,44], greater health information seeking [45], and other positive health-related outcomes, including higher perceived quality of care and increased likelihood of asking questions in a medical appointment [45-47].

There is some evidence that spontaneous self-affirmation may be beneficial for smokers. In one cross-sectional study of U.S. adult smokers, spontaneous self-affirmation moderated the relationship between living in a state with smoke-free policies, which may constitute a threatening environment for smokers, and quit intentions [48]. In this study, we examined whether spontaneous self-affirmation was associated with quit outcomes among a global cohort of smokers enrolled in a UK-based smoking app. In addition, we examined whether the tendency to spontaneously self-affirm moderated the relationship between self-affirmation inductions and successful cessation.

In addition to the tendency to spontaneously self-affirm, other psychological states and individual differences may serve as resources to bolster smoking cessation, either by interacting with self-affirmation or on their own. In this study, we examined optimism and sadness. Optimism refers to a general tendency to expect positive future events [49]. As optimism is a psychological resource that can bolster goal pursuit [50,51], people with higher optimism may have greater success at smoking cessation. Spontaneous self-affirmation and optimism are distinct psychological processes [41]; however, they may have similar associations with health outcomes, extending to smoking cessation [46]. Currently experienced emotions may also influence smoking cessation; such emotions may trigger action tendencies that facilitate predictable patterns of behavior [52-54]. Sadness, in particular, may be a hindrance to quitting smoking and predicting relapse during the smoking cessation process [55]. Sadness is associated with reward-seeking tendencies to mitigate loss [56], which can result in increased hedonically pleasing, but often unhealthy, appetitive behavior [57], including smoking [55]. Thus, when current or former smokers feel sad, they may turn to cigarettes in an attempt to improve their mood. In addition to influencing cessation success, emotion may influence the experience of relapse during the smoking cessation process.

\section{Self-Affirmation and Mobile Health: Creating Scalable Health Behavior Interventions}

Health behavior interventions that are mobile or remotely delivered are easily implemented and widely disseminated, and integrating self-affirmation content could enhance their efficacy. The scalability of self-affirmation interventions has been demonstrated in other domains in which threat impedes adaptive outcomes (eg, education; [58]) but has rarely been examined in health contexts. Indeed, self-affirmation opportunities are disseminable, given that affirmation exercises require little time and effort but can have lasting effects [58,59]. Enduring effects from such a low-burden intervention are hypothesized to work through recursive processes [32]. That is, it is not necessarily the affirmation itself that continues to influence behavior over time. Rather, affirmation attenuates threats to self-competence that might arise from cravings and temporary relapse, which might otherwise impede motivation to quit smoking, and then allows individuals to capitalize on existing resources to facilitate behavior change $[58,60]$. A recent meta-analysis suggested that self-affirmation is more likely to facilitate change when psychological threat impedes behavior change and when resources are present to support such change [32]. Thus, implementing brief affirmations into an existing, scalable cessation intervention in which psychological threat may impede cessation may bolster the effectiveness of the intervention by maximizing the likelihood that individuals will benefit from the behavior change resources provided in the intervention.

\section{Previous Work Informing This Study}

This study was designed as a follow-up to a previous study that provided initial evidence that incorporating a self-affirmation component into a standard text message-based smoking cessation intervention was a feasible, low-cost, and potentially efficacious way of bolstering the content of that intervention [61]. This previous study used a 2 (baseline affirmation: present vs absent) x 2 (integrated affirmation texts: present vs absent) factorial design [61]. In that study, 1261 participants met the eligibility criteria and initiated the program, 687 participants remained enrolled throughout the 42-day intervention, and 81 participants reported their smoking status at the end of the 42-day intervention [61]. Although there were no significant effects of affirmations on cessation when examining participants who remained enrolled in the study $(n=687)$, affirmations did facilitate cessation when only participants who reported their smoking status at the 42-day follow-up were included in analyses $(n=81,6.4 \%$ of eligible baseline respondents) [61]. Intent-to-treat analyses of the 1261 participants who initiated the program indicated a $5.6 \%$ cessation prevalence at the 42 -day follow-up [61]. This study builds on this former work by (1) providing a test of replication and (2) examining the role of individual differences in spontaneous self-affirmation, optimism, and affect.

\section{This Study and Hypotheses}

This study was intended to replicate our team's earlier study (Taber et al [61]) in a different setting. In this study, we tested whether self-affirmation was associated with better cessation outcomes in the context of a smoking cessation app. This study had 2 primary aims: to assess the effect of induced self-affirmation conditions on smoking cessation outcomes (aim 1) and to assess the associations of spontaneous self-affirmation with smoking cessation outcomes (aim 2). We hypothesized that 2 types of self-affirmation opportunities - a baseline kindness quiz and self-affirming push notifications in the subsequent months-would promote cessation. We also hypothesized that individuals with a tendency to spontaneously self-affirm at baseline would be more likely to successfully quit smoking. In the absence of relevant findings on which to base hypotheses, we tested whether induced self-affirmation conditions were more or less effective for people higher versus lower in spontaneous self-affirmation [41]. Finally, an exploratory aim (aim 3) was to assess baseline optimism and baseline affective states (happiness, anger, anxiousness, 
hopefulness, sadness) as potential predictors and potential moderators of the relationship between affirmation conditions and cessation outcomes.

\section{Methods}

\section{Smoke Free App}

Smoke Free-Quit Smoking Now is a UK-based app designed for iOS and Android devices [15] that attracts users from across the globe. The app averages 3000 new downloads a day and allows users to set a quit date and track their craving [15]. The app offers 4 methods by which users can monitor their progress: (1) a calendar showing the total amount of time since they stopped smoking, (2) a calculator that shows the amount of money saved by not buying cigarettes and the number of cigarettes not smoked, (3) virtual badges users can earn for milestones, such as 50 hours smoke-free, and (4) health progress indicators to monitor improvements since cessation [15].

\section{Participants, Recruitment, and Eligibility}

A randomly selected proportion of users who downloaded the app during the study period (initially $10 \%$ and then increased to $30 \%$ to achieve recruitment goals) were shown a consent form and invited to participate in this study. In the informed consent form, participants were told that they could opt out of the study at any point by contacting the study investigator. The study employed a 2 (baseline self-affirmation induction: present vs absent) x 2 (notifications: self-affirming texts vs control texts) double-blind randomized controlled trial (RCT) in which self-affirmation opportunities were added to an existing smoking cessation app. Those who consented were randomly assigned to 1 of the 4 conditions and completed a baseline assessment. The initial recruitment goal was 5000 participants to have 500 completing the 1-month follow-up survey after accounting for $90 \%$ attrition, similar to previous studies [61,62]. A sample size of 500 at the 1-month follow-up was calculated to be able to detect a small effect size $(F=.15)$, with high $(.90)$ power using an analysis of variance (ANOVA) with 4 groups (calculated with G*Power). Participants were asked to complete 2 follow-up assessments 1 month and 3 months after they downloaded the app to assess cessation behavior and smoking status. All data were collected through the smartphone apps-users were notified about follow-up surveys in the app with one push notification and a red dot added to the app icon to indicate user action was requested. The link to complete the survey remained in the Settings section of the app until the participant responded.

Once participants completed the baseline assessment, their eligibility was determined. Participants were not included in the study if they were under 18 years or over 98 years of age, selected a quit date more than 14 days in the future or more than 1 day in the past, paid for additional app features (Pro users), or did not complete the baseline assessment. In a divergence from the previous study [61], potential participants in this study were required to have listed a quit date after the day they downloaded the app; this ensured that participants randomized to the baseline affirmation condition would take the baseline affirmation quiz before attempting cessation. In addition, during data collection, a glitch occurred in which the same identifier was assigned to multiple participants; all users affected by this glitch were excluded from the study and are indicated in Figure 1 under the designation of not meeting inclusion criteria. App users who were not eligible for the study could still use the app. All participants were entered in a lottery-noncontingent on completion of surveys - for a US \$100 Amazon gift card. This study was approved by the Institutional Review Board of the National Cancer Institute. 
Figure 1. Consolidated Standards of Reporting Trials (CONSORT) diagram.

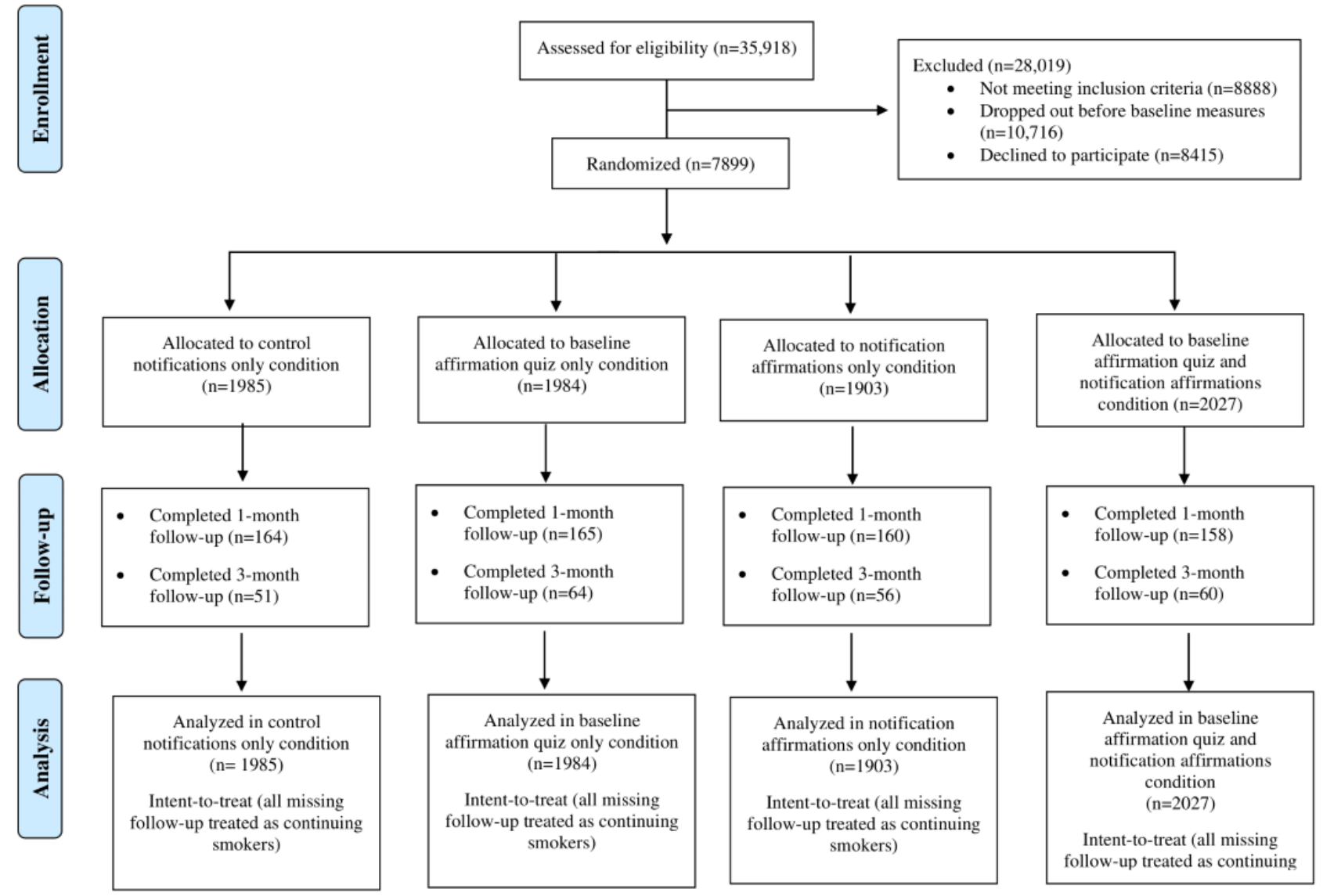

In total, 7899 participants met all inclusion criteria, were enrolled in the study, and provided survey responses. The country of participant residence was not assessed at the individual level; however, aggregate information about the geographic location of participants was available; most participants were from the United Kingdom, closely followed by the United States (Multimedia Appendix 1). Overall, the mean age of participants was 30.5 years (SD 8.7). The majority of participants were male $(4790 / 7899,60.6 \%)$ and did not use any cessation aids other than the Smoke Free app at baseline (6178/7899, 78.2\%). Table 1 shows the demographic characteristics of participants at baseline. Significance assessed in Table 1 used a Bonferroni-corrected $\alpha$ level (.05 and 16 comparisons, so the adjusted $\alpha$ level is $P<.003125$ ). 
Table 1. Baseline characteristics of the study participants $(\mathrm{N}=7899)$.

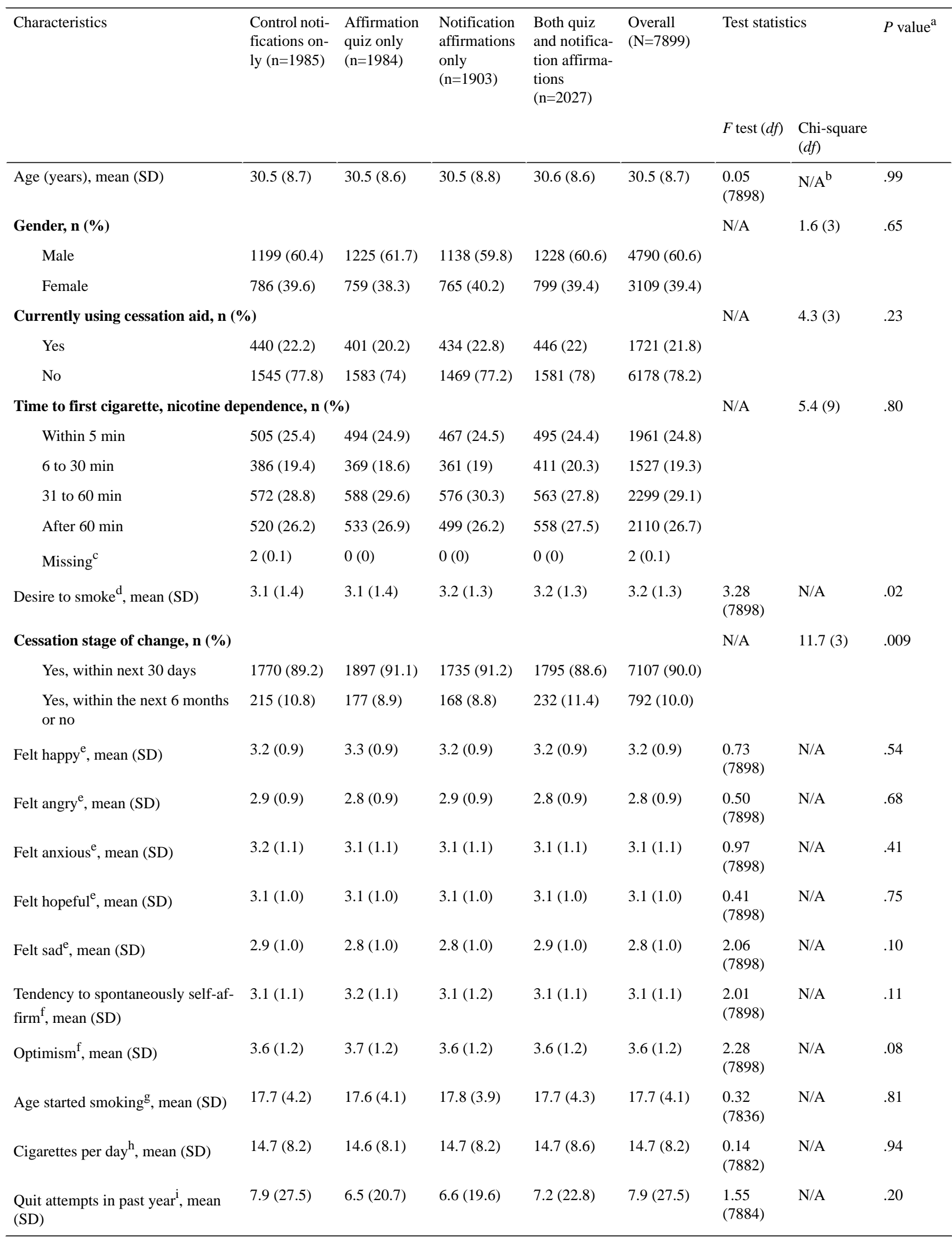

${ }^{\text {a }}$ Significance assessed using the Bonferroni-corrected $\alpha$ level=0.05/16 comparisons $=0.003125$. No variables assessed met the threshold for statistical significance after the Bonferroni correction was applied. 
${ }^{\mathrm{b}}$ N/A: not applicable.

${ }^{\mathrm{c}}$ Respondents who were missing a valid answer for time to first cigarette were included in all subsequent analyses if they had valid data for all other variables.

$\mathrm{d}_{1=\text { not at all; } 5=\mathrm{a} \text { lot. }}$

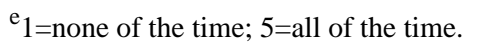

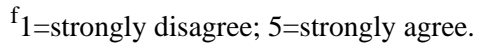

${ }^{\mathrm{g}}$ Age started smoking was a write-in question; all ages from 5 years old to present age were considered valid cases. All ages outside of this range were excluded from analysis of age started smoking but were included in all subsequent analyses.

${ }^{\mathrm{h}}$ Cigarettes per day was a write-in question; all values from 0 to 99 were considered valid cases. All responses outside of this range were excluded from the analysis of cigarettes per day but were included in all subsequent analyses.

${ }^{\mathrm{i}}$ Past-year cessation attempts were assessed via a write-in question; all values from 0 to 365 were considered valid cases. All responses outside of this range were excluded from analysis of past year cessation attempts but were included in all subsequent analyses.

\section{Baseline Measures}

Upon agreeing to participate, participants provided their age, gender, age at which they started smoking, average number of cigarettes smoked per day, smoking cessation aids (if any) they were currently using, and a quit date. Data on race and ethnicity were not collected, in part because the app is available globally and participants came from different countries with different racial and ethnic groups.

Participants were also asked questions to assess potential differences in baseline smoking behavior and levels of addiction. Baseline measures used to compare groups included nicotine dependence (How soon after you wake up do you smoke your first cigarette? [63]) and desire to smoke (How strong is your desire to smoke, right now? with options not at all to a lot on a 5-point scale). Previous quit attempts were assessed (In the last year, how many times have you quit smoking for at least 24 hours?). Smoking cessation stage of change was assessed using the following item: Are you seriously thinking of quitting smoking? with answer choices yes, within the next 30 days, corresponding to the Transtheoretical Model's preparation stage, yes, within the next 6 months, representing the Transtheoretical Model's contemplation stage, and no, not thinking of quitting, corresponding to precontemplation [64]. On the basis of the distribution of responses and our conceptual interest in the effects of self-affirmation among smokers who intend to quit smoking, the stage of change was dichotomized into yes, within the next 30 days and yes, within the next 6 months or no. These items were used to compare groups at baseline for smoking behavior and experiences.

Affect was assessed using items from the Positive and Negative Affect Schedule (PANAS) [65] as adapted by the Midlife in the United States (MIDUS) study [66,67] and the National Cancer Institute (NCI) Health Information National Trends Survey (HINTS). Participants rated their level of happiness, anger, anxiety, sadness, hopefulness, and anxiety within the past 30 days on a 5-point scale from none of the time to all of the time. The affect items were reverse coded so that higher scores indicated experiencing that emotion more often. Participants' tendencies to engage in spontaneous self-affirmation were assessed as the average of 2 items used in previous studies $[45,48]$ from the longer spontaneous self-affirmation measure (SSAM [41]): (1) "When I feel threatened or anxious I find myself thinking about my strengths" and (2) "When I feel threatened or anxious I find myself thinking about my values." Participants' baseline level of optimism was assessed with the item: "I'm always optimistic about my future" [68]. The SSAM and optimism items were assessed on a 5-point scale with the anchors $1=$ strongly agree to $5=$ strongly disagree. However, these items were reverse coded so that higher scores indicated more agreement and thus higher optimism.

\section{Follow-Up Surveys (1 and 3 Months)}

All participants were invited to complete a 1-month and 3-month follow-up survey to assess smoking status. Both follow-up surveys assessed smoking status with the items: "Have you smoked at all in the past month?" and "Have you smoked at all in the past week?" Response options for both questions were "no, not a puff," "1-5 cigarettes," or "more than 5 cigarettes." For these analyses, responses were dichotomized to indicate no smoking or smoking (1 cigarette or more) in the time period. In addition, participants were asked to report the average number of cigarettes smoked per day, time to first cigarette, and if they were using any other cessation aids at follow-up.

\section{Baseline Self-Affirmation Questionnaire}

Participants assigned to the baseline affirmation conditions were shown a shortened, 5-item kindness questionnaire (quiz), adapted from previous work $[61,69]$, directly after the baseline questionnaire. The purpose of this quiz was to induce self-affirmation by allowing participants to respond yes to having engaged in specific instances of past kindness. In the original questionnaire, participants were asked to provide written examples for each item to which they responded affirmatively; however, participants in this study were not asked to provide examples. This self-affirmation induction has been frequently used, has face validity, and is easy to implement [70]. The control condition did not receive the kindness quiz or any content in its place. The full self-affirmation questionnaire as well as responses by condition is presented in Multimedia Appendix 2. Of the respondents who received the baseline kindness quiz, approximately $83.1 \%$ (3333/4011) answered yes to 4 of the 5 items (Multimedia Appendix 2).

\section{Affirmation and Control Push Notifications}

Participants in the control push notification condition received general tips related to quitting smoking, whereas participants in the affirmation push notifications condition received affirming messages from a pool of 15 possible notifications. The affirmation messages were based on literature and a previous study of self-affirmation content that had been integrated into a text messaging intervention for smoking cessation [61]. The control notifications were informed by the smoking cessation 
literature [71,72]. Participants received 2 notifications (either self-affirmation or control, depending on their assigned condition) per day for the duration of the study, unless they turned off notifications, which was the same as the frequency of notifications in the current version of the app. One notification was sent during each of the following time blocks: 8 AM to 2:30 PM and 2:31 PM to 9 PM. Participants were able to change the earliest and latest time for the notification (eg, change $8 \mathrm{AM}$ to $7 \mathrm{AM}$ or $9 \mathrm{PM}$ to $11 \mathrm{PM}$ ). Participants could also access these self-affirmation or control messages (depending on condition) every time they reported experiencing a craving on a Tips screen. The full text of all notifications, organized by category, is presented in Multimedia Appendix 3.

\section{Analysis}

All analyses were conducted using Stata 16 [73]. First, attrition rates were calculated for each of the 4 induced self-affirmation conditions. Second, demographic characteristics and baseline survey responses were compared across groups using ANOVA and chi-square tests. Third, a series of binary logistic regression models were run to examine predictors of successful cessation and potential moderating factors. All regression analyses used intent-to-treat, such that respondents who did not provide follow-up data were treated as continuing smokers. We elected to use intent-to-treat because it is widely used for assessing smoking cessation in interventions [8,9] and tends to be more conservative in assuming that all participants lost to follow-up continued to smoke instead of artificially inflating the cessation rate by removing participants lost to follow-up from analyses. We adopted $P=.05$ as our cut-off for statistical significance, with Bonferroni corrections applied for multiple comparisons as necessary.

\section{Trial Registration}

The trial was retrospectively registered at ISRCTN: https://www.isrctn.com/ISRCTN56646695.

\section{Results}

\section{Enrollment, Attrition, and Participant Characteristics}

A CONSORT (Consolidated Standards of Reporting Trials) diagram is provided to show subject enrollment and study completion (Figure 1). Overall, 8.2\% (647/7899) of users who enrolled in the study completed the 1-month follow-up survey and $2.9 \%$ (231/7899) completed the 3-month survey (Table 2), consistent with systematic reviews that found high levels of attrition in web-based RCTs [74]. The proportion of users who completed the follow-up was lower than in previous studies of this same app in which $7.5 \%$ of participants completed a 3-month follow-up [15]; however, the sample size in this study was considerably smaller. Attrition in this study was similar to attrition in a similar previous study in which $6.4 \%$ of participants completed a 42-day follow-up [61]. Although we estimated $90 \%$ attrition in our power calculations, we exceeded this percentage. In addition, there were more follow-up assessments in this study and it was available to Android but not iOS users, in contrast with the previous study [15], which had fewer and shorter follow-up assessments and enrolled both iOS and Android users. It is possible that the more frequent follow-ups combined with differences between the iOS and Android app can help contextualize this finding. Follow-up rates did not differ significantly by condition ( 1 month: $\chi_{3}^{2}=0.6, P=.90 ; 3$ months: $\chi_{3}^{2}=1.5, P=.68$; Table 2). This paper presents analyses for both the 1- and 3-month follow-ups; however, as the 3-month follow-up rates were considerably lower than the 1-month follow-up rates, most implications and conclusions focus on results from the 1-month follow-up.

Table 2. Attrition and cessation rates by study condition ( $\mathrm{N}=7899)$.

\begin{tabular}{|c|c|c|c|c|c|c|c|}
\hline Outcome & $\begin{array}{l}\text { Control notifi- } \\
\text { cations only }\end{array}$ & $\begin{array}{l}\text { Affirmation } \\
\text { quiz only }\end{array}$ & $\begin{array}{l}\text { Notification } \\
\text { affirmations } \\
\text { only }\end{array}$ & $\begin{array}{l}\text { Both quiz and no- } \\
\text { tification affirma- } \\
\text { tions }\end{array}$ & Overall & $\begin{array}{l}\text { Test statistic, } \\
\text { chi square } \\
(d f)\end{array}$ & $\begin{array}{l}P \text { val- } \\
\text { ue }\end{array}$ \\
\hline Completed baseline survey, $\mathrm{n}$ & 1985 & 1984 & 1903 & 2027 & 7899 & $-^{\mathrm{a}}$ & - \\
\hline Completed 1-month follow-up, n (\%) & $164(8.3)$ & $165(8.3)$ & $160(8.4)$ & $158(7.8)$ & $647(8.2)$ & $0.6(3)$ & .90 \\
\hline Past week cessation at 1 month & $145(7.3)$ & $143(7.2)$ & $139(7.3)$ & $142(7.0)$ & $569(7.2)$ & $0.2(3)$ & .98 \\
\hline Past month cessation at 1 month & $133(6.7)$ & $128(6.5)$ & $128(6.7)$ & $114(5.6)$ & $503(6.4)$ & $2.7(3)$ & .44 \\
\hline Completed 3-month follow-up, n (\%) & $51(2.6)$ & $64(3.2)$ & $56(2.9)$ & $60(3.0)$ & $231(2.9)$ & $1.5(3)$ & .68 \\
\hline Past week cessation at 3 months & $48(2.4)$ & $58(2.9)$ & $55(2.9)$ & $54(2.7)$ & $215(2.7)$ & $1.2(3)$ & .75 \\
\hline Past month cessation at 3 months & $38(1.9)$ & $49(2.5)$ & $48(2.5)$ & $46(2.3)$ & $181(2.3)$ & $2.0(3)$ & .57 \\
\hline
\end{tabular}

${ }^{\mathrm{a}}$ No statistical tests were run.

\section{Smoking Cessation and Baseline Differences}

Cessation rates did not differ significantly between groups at the 1-month (past-week cessation: $\chi_{3}^{2}=0.2, P=.98$; past-month cessation: $\chi_{3}^{2}=2.7, P=.44$; Table 2) or 3-month (past week cessation: $\chi_{3}^{2}=1.2, P=.75$; past month cessation: $\chi_{3}^{2}=2.0, P=.57$;
Table 2) follow-up. Using an intent-to-treat analysis, the overall past-week cessation rate was $7.2 \%$ (569/7899) and the past-month cessation rate was $6.4 \%(503 / 7899)$ at the 1 -month follow-up (Table 2). This is similar to the previous study of a text messaging program with affirmation content, which found $5.6 \%$ cessation at 6 weeks using intent-to-treat analysis [61]. Notably, despite randomization, participants differed in baseline 
desire to smoke $\left(F_{7898}=3.28 ; P=.02\right.$; Table 1$)$ and cessation stage of change $\left(\chi_{3}^{2}=11.7 ; P=.009\right.$; Table 1$)$ across conditions, although neither met the threshold for statistical significance after the Bonferroni correction was applied. The Bonferroni correction is conservative; because cessation stage of change differed at the $P<.01$ level and is likely related to the smoking cessation outcome, subsequent regression analyses controlled for baseline cessation stage of change.

\section{Aims 1 and 2: Self-Affirmation's Associations With Cessation Outcomes}

The primary aim of this study was to assess the impact of induced self-affirmation conditions on smoking cessation. The secondary aim of this study was to assess the associations of spontaneous self-affirmation with smoking cessation. To assess factors associated with cessation, binary logistic regression models were run using one of the 2 main outcomes (past-week cessation at 1 month and past-month cessation at 1 month) as the dependent variable. The 2 main 1-month outcomes were strongly correlated $(r=0.93)$. In both regression models, tendency to spontaneously self-affirm at baseline was a significant predictor of cessation (Table 3), consistent with the hypotheses. However, neither self-affirmation study condition nor their interaction was significant in these models, indicating that providing opportunities for self-affirmation in the smoking cessation smartphone app did not result in a greater likelihood of cessation than using the smartphone app without affirmation.

Table 3. Primary self-affirmation regression models ( $N=7899)$.

\begin{tabular}{|c|c|c|c|c|c|c|}
\hline \multirow[t]{2}{*}{ Variable } & \multicolumn{3}{|c|}{ Past-week cessation at 1 month } & \multicolumn{3}{|c|}{ Past-month cessation at 1 month } \\
\hline & $\mathrm{OR}^{\mathrm{a}}(95 \% \mathrm{CI})$ & SE & $P$ value & OR $(95 \% \mathrm{CI})$ & SE & $P$ value \\
\hline Baseline affirmation & $0.99(0.78-1.26)$ & 0.1 & .92 & $0.96(0.75-1.24)$ & 0.1 & .76 \\
\hline Notification affirmations & $0.99(0.77-1.26)$ & 0.1 & .92 & $0.99(0.77-1.28)$ & 0.1 & .97 \\
\hline Baseline and notification affirmations interaction & $0.98(0.70-1.38)$ & 0.2 & .90 & $0.87(0.60-1.12)$ & 0.2 & .44 \\
\hline Cessation stage of change: Yes, within the next 6 months or $\mathrm{No}^{\mathrm{b}}$ & $0.80(0.59-1.10)$ & 0.1 & .17 & $0.85(0.62-1.18)$ & 0.1 & .40 \\
\hline Spontaneous self-affirmation & $0.85(0.79-0.92)$ & 0.0 & $<.001^{\mathrm{c}}$ & $0.90(0.83-0.97)$ & 0.0 & $.01^{\mathrm{d}}$ \\
\hline
\end{tabular}

${ }^{\mathrm{a} O R}$ : odds ratio.

${ }^{\mathrm{b}}$ Reference category: Yes, within the next 30 days.

${ }^{\mathrm{c}} P<.001$.

${ }^{\mathrm{d}} P<.05$.

In addition, despite low follow-up rates, both 3-month outcomes were also explored. There was a similarly high association between past-week and past-month cessation at the 3-month follow-up $(r=0.91)$. None of the self-affirmation measures (tendency to spontaneously self-affirm, baseline affirmation condition, notification affirmation condition, the interaction of baseline, and notification affirmations) significantly predicted cessation in the main 3-month models (Multimedia Appendix 4).

Subsequently, we ran models testing a three-way interaction between our self-affirmation study conditions and spontaneous self-affirmation with both the 1-month and 3-month outcomes. This interaction was not significant, establishing that spontaneous self-affirmation did predict 1-month cessation in this study, but did not moderate the relationship between study conditions and cessation outcomes.

\section{Aim 3: Examining Potential Predictors and Moderators}

The goal of exploratory aim 3 was to assess baseline optimism and baseline affective states as potential predictors and moderators of the relationship between affirmation conditions and cessation outcomes. To test this aim, we conducted regression analyses in which optimism and each of the 5 affective states (happiness, anger, anxiousness, hopefulness, sadness) were simultaneously added to the main regression models (Table 4). That is, we tested whether these factors predicted 1-week and 1-month cessation at 1 month when controlling for spontaneous self-affirmation, baseline affirmation condition, notification affirmation condition, their interaction, and cessation stage of change. In this model, tendency to spontaneously self-affirm still significantly predicted past-week cessation at the 1 -month follow-up $(P<.001)$ but did not significantly predict past-month cessation at the 1-month follow-up, although this association approached significance $(P=.05)$. Lower sadness was a significant predictor of successful cessation at the 1-month follow-up for both past-week and past-month cessation ( $P=.002$ and $P=.007$, respectively). Optimism predicted past-week cessation at the 1-month follow-up $(P=.04)$ and both happiness and anger predicted past-month cessation at the 1-month follow-up ( $P=.03$ for both). We also ran these with each potential predictor assessed separately and the results did not differ from the simultaneous model presented in Table 4. 
Table 4. Regression models with potential predictors $(\mathrm{N}=7899)$.

\begin{tabular}{|c|c|c|c|c|c|c|}
\hline \multirow[t]{2}{*}{ Variable } & \multicolumn{3}{|c|}{ Past-week cessation at 1 month } & \multicolumn{3}{|c|}{ Past-month cessation at 1 month } \\
\hline & $\mathrm{OR}^{\mathrm{a}}(95 \% \mathrm{CI})$ & SE & $P$ value & OR $(95 \% \mathrm{CI})$ & SE & $P$ value \\
\hline Baseline affirmation & $0.97(0.77-1.24)$ & 0.1 & .83 & $0.95(0.74-1.22)$ & 0.1 & .68 \\
\hline Notification affirmations & $0.98(0.77-1.25)$ & 0.1 & .87 & $0.99(0.77-1.27)$ & 0.1 & .92 \\
\hline Baseline and notification affirmations interaction & $1.00(0.71-1.40)$ & 0.2 & .98 & $0.88(0.61-1.26)$ & 0.2 & .48 \\
\hline Cessation stage of change: Yes, within the next 6 months or $\mathrm{No}^{\mathrm{b}}$ & $0.81(0.59-1.11)$ & 0.1 & .19 & $0.86(0.63-1.19)$ & 0.1 & .37 \\
\hline Spontaneous self-affirmation & $0.86(0.79-0.94)$ & 0.0 & $<.001^{\mathrm{c}}$ & $0.91(0.84-1.00)$ & 0.0 & .05 \\
\hline Optimism & $0.92(0.85-0.99)$ & 0.0 & $.04^{\mathrm{d}}$ & $0.93(0.85-1.00)$ & 0.0 & .09 \\
\hline Happy & $1.05(0.93-1.18)$ & 0.1 & .42 & $0.91(0.83-0.99)$ & 0.0 & $.03^{\mathrm{d}}$ \\
\hline Angry & $0.90(0.80-1.01)$ & 0.1 & .06 & $0.87(0.78-0.99)$ & 0.1 & $.03^{\mathrm{d}}$ \\
\hline Anxious & $0.97(0.88-1.06)$ & 0.1 & .48 & $0.97(0.88-1.08)$ & 0.1 & .61 \\
\hline Hopeful & $1.04(0.94-1.14)$ & 0.1 & .47 & $1.03(0.93-1.14)$ & 0.1 & .56 \\
\hline Sad & $0.84(0.75-0.93)$ & 0.1 & $.002^{\mathrm{d}}$ & $0.85(0.76-0.96)$ & 0.1 & $.007^{\mathrm{d}}$ \\
\hline
\end{tabular}

${ }^{\mathrm{a} O R}$ : odds ratio.

${ }^{\mathrm{b}}$ Reference category: Yes, within the next 30 days.

${ }^{\mathrm{c}} P<.001$.

$\mathrm{d}_{P<.05 \text {. }}$

Next, moderation analyses were conducted, with a three-way interaction term (baseline affirmation, notification affirmation, and potential moderator) for each of the affective states and optimism, run separately. No three-way interaction was significant. The full model for sadness is provided as an appendix (Multimedia Appendix 5); however, the models for other affective states and optimism have not been included because of space limitations.

We then conducted parallel analyses with the 3-month outcomes. None of the affective states were significant predictors of cessation in the past week or month at the 3-month follow-up; however, optimism was a predictor of cessation for both past-week and past-month cessation at the 3-month follow-up $(P=.004$ and $P=.002$, respectively; Multimedia Appendix 4). Due to low follow-up rates at the 3-month follow-up, potential moderation was not explored with the 3-month outcomes.

\section{Association of Spontaneous Self-Affirmation With Dependence}

Previous work has found that smokers with a greater tendency to spontaneously self-affirm report more quit attempts and higher quit intentions, particularly when they live in states with more comprehensive smoke-free laws, highlighting factors that affect the cessation process [48]. Due to the significant effects of spontaneous self-affirmation in our study, we undertook additional analyses. The mean spontaneous self-affirmation scores in our study (mean 3.11 out of 5, SD 1.1) were comparable with those of past studies (mean 2.75 out of 4, SD 0.14 [46]; mean 3.12 out of 5, SD 0.86 [75]).

We examined whether spontaneous self-affirmation was associated with several dependence and quit intention measures in our sample to assess whether respondents who had a greater

tendency to spontaneously self-affirm were less dependent on nicotine or had a stronger desire to quit at baseline, offering them an advantage. We computed correlations of spontaneous self-affirmation with the cessation stage of change, time to first cigarette, and quit intention. All were small (all correlation coefficient values were less than 0.1), indicating that smokers higher in tendency to self-affirm in this study were not necessarily less addicted or more intent to quit at baseline than smokers with lower tendencies to self-affirm.

\section{Discussion}

\section{Principal Findings}

In this study, opportunities for self-affirmation provided in the smartphone app (baseline self-affirmation quiz and self-affirmation notifications) did not significantly improve the likelihood of successful cessation. However, tendency to spontaneously self-affirm was a strong and significant predictor of cessation. Baseline sadness was associated with a lower likelihood of reporting successful cessation at the 1-month follow-up; optimism was significantly associated with past-week cessation at the 1-month follow-up, and happiness and anger were both significantly associated with past-month cessation at the 1-month follow-up. There were no interactions between any explored individual difference predictor and study conditions.

The spontaneous self-affirmation findings are consistent with previous findings that spontaneous self-affirmation was associated with improved psychological well-being and health care experiences $[45,46]$, both of which may play a role in the smoking cessation process. In addition, although previous studies have found a relationship between spontaneous self-affirmation and quit attempts and intentions [48], we did not find a relationship between spontaneous self-affirmation 
and any dependence or quit measure in our sample. Thus, any association of spontaneous self-affirmation with quitting was not due to dependence or past quit attempts. Future work should explore this relationship in more detail to understand the specific benefit and ways to help smokers who do not tend to spontaneously self-affirm.

\section{Comparison With Previous Work}

This study differs from previous smoking self-affirmation studies that typically provide participants with information about the negative health consequences of smoking. In this study, no explicitly threatening health information or loss-framed messages were provided, consistent with the positive focus of the app. The messages conveyed the benefits of quitting instead of the harms of smoking and were not hypothesized to constitute explicitly threatening health information. We did not directly assess whether participants perceived any of the material in the app to be threatening. One recent meta-analysis found that self-affirmation is less likely to facilitate change when psychological threat is minimal [32], which suggests that self-affirmation opportunities may have been less effective in this study in the absence of directly threatening information. Moreover, smokers may be aware of the health costs of smoking, and it is unknown to what extent information about the health consequences is novel to smokers, which could help to explain null self-affirmation effects in previous studies of smokers. These studies would benefit from pilot testing to determine whether threatening information about the health consequences of smoking is indeed perceived by smokers as threatening and novel. An alternative explanation is that our control messages were received well by respondents, offsetting our ability to observe any benefit of the self-affirmation messages.

Previous studies have reported mixed findings concerning whether self-affirmation inductions can assist smokers trying to quit; some studies have found benefits [28,30,33-35], whereas others have not $[35,39,40,76]$. Our finding that induced self-affirmations did not influence smoking behavior is consistent with multiple other studies that have shown null or even backfiring effects among smokers who undergo self-affirmation interventions [35]. It is possible that our baseline affirmation quiz and notification affirmations did not induce self-affirmation in participants; consistent with previous self-affirmation intervention studies, no manipulation check for affirmation was included, and it is difficult to assess whether participants were successfully affirmed. The original kindness quiz asks respondents to write down a specific time they engaged in the aforementioned action [69]. In this study, the baseline kindness quiz was adapted to ask participants to answer yes or no without explicitly asking them to write or think of an example, given that the affirmation intervention occurred through text messages.

It is a challenge to determine how best to adapt self-affirmation interventions developed in laboratory settings to the real world. In a previous study testing whether various adaptations of the kindness quiz differentially affected health cognitions and smoking intentions among a sample of online smokers, there were no significant differences depending on whether participants were asked to write examples, imagine examples, or were not asked to provide any examples [35]. However, that study also found that none of the self-affirmation conditions were more effective than the control conditions [35]. In addition, participants asked to provide written self-affirmation responses endorsed fewer affirmation questions than those not asked to provide written examples, suggesting that the writing was onerous [35]. In that study, for participants providing written examples, the intervention took nearly 7 times longer than it did for participants not asked to provide examples [35]. Thus, more research is needed to determine how to administer effective self-affirmation interventions to participants not in laboratory settings.

Our finding that additional opportunities for self-affirmation added to the smartphone app in this study did not have effects could be due to multiple factors. The self-affirmation content may not have been as noticeable as self-affirmations in other studies, given that participants did not complete the study in a more controlled laboratory setting. In addition, participants may have skimmed or otherwise not engaged with the self-affirmation content in this study. We also do not have data on the extent to which participants read or engage with induced self-affirmation materials. In addition, the existing app material was evidence-based and has already been found to be relatively effective on its own [15], thus identifying additional benefits of novel self-affirmation intervention material may have been difficult.

This study complements existing evidence concerning the distinctiveness of spontaneous self-affirmation from other psychological resources, such as optimism [41]. In this study, the single-item measure of optimism was only moderately correlated with spontaneous self-affirmation $(r=0.46)$. Some previous work using a small number of items has found that spontaneous self-affirmation is related to greater optimism [46]. However, the correlation between the full measure of spontaneous self-affirmation and optimism is small (eg, $r=0.22$ as observed in a study by Harris et al [41]). Furthermore, cancer survivors who reported greater optimism reported better physical, mental, and cognitive health, even when controlling for spontaneous self-affirmation [77]. In this study, spontaneous self-affirmation was a significant predictor of 1-month cessation outcomes, whereas optimism was unrelated to 1-month cessation outcomes but predicted 3-month cessation outcomes. Optimism facilitates pursuit of goals [50,51], so it is noteworthy that it was not associated with smoking cessation goals at 1 month, whereas spontaneous self-affirmation did maintain such an association.

Interestingly, baseline sadness was significantly related to cessation outcomes at the 1-month follow-up. Feeling sadness less frequently at baseline was associated with a greater likelihood of reporting both past-week and past-month cessation. The relationship between sadness and cessation outcomes is consistent with previous theory and research suggesting that sadness facilitates reward-seeking tendencies that might undermine healthy behavior, including smoking cessation [55-57]. Optimism and all affective states (happiness, anger, anxiousness, hopefulness, sadness) were not found to moderate the relationship between the assigned affirmation conditions and successful cessation. Previous work has found that clinical 
diagnoses of anhedonia and depressed mood predict increased odds of relapse among smokers trying to quit [78]; however, this study is among the first to examine specific affective states and their association with successful cessation. Future work can further disentangle the relationship between sadness and cessation experiences.

\section{Limitations}

This study has several limitations. As previously discussed, we do not have data concerning whether participants were successfully affirmed and to what extent they were engaged by the intervention. There are several methodological limitations. As data were collected from all users who downloaded the smartphone app, it was difficult to maintain strict experimental control. We were not able to monitor if or when participants turned off notifications, so we were unable to assess an individual's exposure to the notification content. We were also unable to determine the geographic location of individual participants and were only able to access aggregate geographic information for the sample. Participants came largely from the United Kingdom and the United States, but there were participants from 8 other countries. In addition, smoking cessation is a complex process, and whereas many users who completed the baseline assessments did not complete follow-up assessments, we were not able to analytically determine why these participants discontinued responding and if they had deleted the smartphone app due to successful cessation or another reason. Another limitation is the use of 1 or 2 -item measures of key constructs, such as spontaneous self-affirmation. However, these items have shown significant associations with outcomes in other studies [41], thus providing support for their validity. Similarly, we only assessed affect once at baseline. Emotions fluctuate over time, particularly during the difficult smoking cessation process. Future studies can monitor changes in affect during the process, such as with daily dairies, to better understand the role that affects plays in cessation. Finally, the attrition experienced in this study was higher than expected based on previous similar studies $[15,61,74]$. In this study, we found that $8.2 \%$ (647/7899) of users who enrolled in the study completed the 1-month follow-up survey and 2.9\% (231/7899) completed the 3-month survey, which is lower than the $7.5 \%$ of participants who completed a 3-month follow-up during a previous trial of this same app [15]. In a previous study that informed the present study, $6.4 \%$ of participants completed a 42-day follow-up [61]. High attrition limits the interpretability of results such that it may have made it difficult to detect and reduce the generalizability of results, particularly at the 3-month follow-up. Furthermore, the intent-to-treat approach assumes that nonresponders are smokers, whereas it could be the case that nonresponders found the protocol burdensome.

However, these limitations are offset by several considerable strengths of this study. This study used a sample of real-life users, which allows for an assessment of how the app will function outside of a highly controlled laboratory setting. The study was also theoretically driven and provides preliminary evidence for the promise of spontaneous self-affirmation in smoking cessation. An additional strength of this study comes from the use of an already-existing, successful smoking cessation app with the addition of self-affirmation specific content.

\section{Conclusions}

The results of this study provide evidence that spontaneous self-affirmation may be an important threat management psychological resource in the context of smoking cessation. They indicate the difficulties of creating effective self-affirmation inductions in smoking apps. There is a need to examine the effectiveness of smartphone app-delivered self-affirmations and to develop more effective affirmations in future dissemination work.

\section{Conflicts of Interest}

$\mathrm{DC}$ is originator of the Smoke Free app and derives income from it.

\section{Multimedia Appendix 1}

Geographic locations of the participants.

[DOCX File , 62 KB-Multimedia Appendix 1]

\section{Multimedia Appendix 2}

Baseline self-affirmation questionnaire and responses by condition.

[DOCX File, 34 KB-Multimedia Appendix 2]

\section{Multimedia Appendix 3}

Text notifications by study condition.

[DOCX File, 35 KB-Multimedia Appendix 3]

\section{Multimedia Appendix 4}

Regression models for 3-month outcomes.

[DOCX File , $41 \mathrm{~KB}-$ Multimedia Appendix 4] 


\section{Multimedia Appendix 5}

Regression models to explore sadness as a potential moderator of self-affirmation conditions.

[DOCX File, 37 KB-Multimedia Appendix 5]

\section{Multimedia Appendix 6}

CONSORT-EHEALTH (V.1.6) checklist.

[PDF File (Adobe PDF File), 1620 KB-Multimedia Appendix 6]

\section{References}

1. Drope J, Schluger N, Cahn Z, Drope J, Hamill S, Islami F, et al. Chapter 8: Deaths. In: The Tobacco Atlas. Atlanta, GA: American Cancer Society; 2018:28.

2. Henley SJ, Thomas CC, Sharapova SR, Momin B, Massetti GM, Winn DM, et al. Vital signs: disparities in tobacco-related cancer incidence and mortality — United States, 2004-2013. MMWR Morb Mortal Wkly Rep 2016 Nov 11;65(44):1212-1218. [doi: 10.15585/mmwr.mm6544a3]

3. Babb S, Malarcher A, Schauer G, Asman K, Jamal A. Quitting smoking among ddults - United States, 2000-2015. MMWR Morb Mortal Wkly Rep 2017 Jan 06;65(52):1457-1464 [FREE Full text] [doi: 10.15585/mmwr.mm6552a1] [Medline: 28056007]

4. Centers for Disease ControlPrevention (CDC). Quitting smoking among adults--United States, 2001-2010. MMWR Morb Mortal Wkly Rep 2011 Nov 11;60(44):1513-1519 [FREE Full text] [Medline: 22071589]

5. Fiore M, Jaén C, Baker T. Evidence and recommendations, treatment elements. In: Treating Tobacco Use and Dependence: 2008 Update. Clinical Practice Guideline. Rockville, MD: US Department of Health and Human Services. Public Health Service; May 2008:100-103.

6. Lancaster T, Stead L. Individual behavioural counselling for smoking cessation. Cochrane Database Syst Rev 2017 Mar 31(3):1-68. [doi: 10.1002/14651858.cd001292.pub3] [Medline: 28361496]

7. Piasecki TM. Relapse to smoking. Clin Psychol Rev 2006 Mar;26(2):196-215. [doi: 10.1016/j.cpr.2005.11.007] [Medline: 16352382]

8. Fraser D, Kobinsky K, Smith SS, Kramer J, Theobald WE, Baker TB. Five population-based interventions for smoking cessation: a MOST trial. Transl Behav Med 2014 Dec;4(4):382-390. [doi: 10.1007/s13142-014-0278-8] [Medline: 25584087]

9. Spohr SA, Nandy R, Gandhiraj D, Vemulapalli A, Anne S, Walters ST. Efficacy of SMS text message interventions for smoking cessation: a meta-analysis. J Subst Abuse Treat 2015 Sep;56:1-10. [doi: 10.1016/j.jsat.2015.01.011] [Medline: 25720333]

10. Whittaker R, McRobbie H, Bullen C, Rodgers A, Gu Y. Mobile phone-based interventions for smoking cessation. Cochrane Database Syst Rev 2016 Apr 10;4:1-52 [FREE Full text] [doi: 10.1002/14651858.CD006611.pub4] [Medline: 27060875]

11. Mobile Fact Sheet. Pew Research Center. 2019 Jun 12. URL: https://www.pewresearch.org/internet/fact-sheet/mobile/ [accessed 2020-12-22]

12. Fox, S. The social life of health information. Pew Research Center. 2014 Jan 15. URL: https://www.pewresearch.org/ fact-tank/2014/01/15/the-social-life-of-health-information/ [accessed 2020-12-22]

13. Tan SS, Goonawardene N. Internet health information seeking and the patient-physician relationship: a systematic review. J Med Internet Res 2017 Jan 19;19(1):e9 [FREE Full text] [doi: 10.2196/jmir.5729] [Medline: 28104579]

14. Ubhi HK, Kotz D, Michie S, van Schayck OC, Sheard D, Selladurai A, et al. Comparative analysis of smoking cessation smartphone applications available in 2012 versus 2014. Addict Behav 2016 Jul;58:175-181 [FREE Full text] [doi: 10.1016/j.addbeh.2016.02.026] [Medline: 26950256]

15. Crane D, Ubhi HK, Brown J, West R. Relative effectiveness of a full versus reduced version of the 'Smoke Free' mobile application for smoking cessation: an exploratory randomised controlled trial. F1000Res 2018;7:1524 [FREE Full text] [doi: 10.12688/f1000research.16148.2] [Medline: 30728950]

16. US Department of Health and Human Services. The Health Consequences of Smoking-50 Years of Progress: A Report of the Surgeon General. Atlanta, GA: US Department of Health and Human Services, Centers for Disease Control and Prevention, National Center for Chronic Disease Prevention and Health Promotion, Office on Smoking and Health; 2014:1-943.

17. Minami H, Yeh VM, Bold KW, Chapman GB, McCarthy DE. Relations among affect, abstinence motivation and confidence, and daily smoking lapse risk. Psychol Addict Behav 2014 Jun;28(2):376-388 [FREE Full text] [doi: 10.1037/a0034445] [Medline: 24955665]

18. Gwaltney CJ, Metrik J, Kahler CW, Shiffman S. Self-efficacy and smoking cessation: a meta-analysis. Psychol Addict Behav 2009 Mar;23(1):56-66 [FREE Full text] [doi: 10.1037/a0013529] [Medline: 19290690]

19. Steele C. The psychology of self-affirmation: sustaining the integrity of the self. Adv Exp Soc Psychol 1988;21:261-302. [doi: 10.1016/S0065-2601(08)60229-4]

20. Liberman A, Chaiken S. Defensive processing of personally relevant health messages. Pers Soc Psychol Bull 2016 Jul 02;18(6):669-679. [doi: 10.1177/0146167292186002] 
21. van 't Riet J, Ruiter RA. Defensive reactions to health-promoting information: an overview and implications for future research. Health Psychol Rev 2013 May;7(sup1):S104-S136. [doi: 10.1080/17437199.2011.606782]

22. Jemmott JB, Ditto PH, Croyle RT. Judging health status: effects of perceived prevalence and personal relevance. J Pers Soc Psychol 1986 May;50(5):899-905. [doi: 10.1037//0022-3514.50.5.899] [Medline: 3712230]

23. Kunda Z. Motivated inference: self-serving generation and evaluation of causal theories. J Pers Soc Psychol 1987;53(4):636-647. [doi: 10.1037/0022-3514.53.4.636]

24. Erceg-Hurn D, Steed L. Does exposure to cigarette health warnings elicit psychological reactance in smokers? J Appl Soc Psychol 2011;41(1):219-237. [doi: 10.1111/j.1559-1816.2010.00710.x]

25. Hall MG, Sheeran P, Noar SM, Ribisl KM, Bach LE, Brewer NT. Reactance to health warnings scale: development and validation. Ann Behav Med 2016 Oct;50(5):736-750 [FREE Full text] [doi: 10.1007/s12160-016-9799-3] [Medline: $\underline{27333895]}$

26. Oakes W, Chapman S, Borland R, Balmford J, Trotter L. 'Bulletproof skeptics in life's jungle': which self-exempting beliefs about smoking most predict lack of progression towards quitting? Prev Med 2004 Oct;39(4):776-782. [doi: 10.1016/j.ypmed.2004.03.001] [Medline: 15351545 ]

27. Sherman DA, Nelson LD, Steele CM. Do messages about health risks threaten the self? Increasing the acceptance of threatening health messages via self-affirmation. Pers Soc Psychol Bull 2016 Jul 02;26(9):1046-1058. [doi: $10.1177 / 01461672002611003]$

28. Harris PR, Mayle K, Mabbott L, Napper L. Self-affirmation reduces smokers' defensiveness to graphic on-pack cigarette warning labels. Health Psychol 2007;26(4):437-446. [doi: 10.1037/0278-6133.26.4.437]

29. Klein WM, Lipkus IM, Scholl SM, McQueen A, Cerully JL, Harris PR. Self-affirmation moderates effects of unrealistic optimism and pessimism on reactions to tailored risk feedback. Psychol Health 2010 Dec;25(10):1195-1208 [FREE Full text] [doi: 10.1080/08870440903261970] [Medline: 20204982]

30. Epton T, Harris PR, Kane R, van Koningsbruggen GM, Sheeran P. The impact of self-affirmation on health-behavior change: a meta-analysis. Health Psychol 2015 Mar;34(3):187-196. [doi: 10.1037/hea0000116] [Medline: 25133846]

31. Sweeney AM, Moyer A. Self-affirmation and responses to health messages: a meta-analysis on intentions and behavior. Health Psychol 2015 Feb;34(2):149-159. [doi: 10.1037/hea0000110] [Medline: 25089345]

32. Ferrer RA, Cohen GL. Reconceptualizing self-affirmation with the trigger and channel framework: lessons from the health domain. Pers Soc Psychol Rev 2019 Aug;23(3):285-304. [doi: 10.1177/1088868318797036] [Medline: 30295141]

33. Armitage CJ, Harris PR, Hepton G, Napper L. Self-affirmation increases acceptance of health-risk information among UK adult smokers with low socioeconomic status. Psychol Addict Behav 2008 Mar;22(1):88-95. [doi: 10.1037/0893-164X.22.1.88] [Medline: 18298234]

34. Pietersma S, Dijkstra A. Cognitive self-affirmation inclination: an individual difference in dealing with self-threats. Br J Soc Psychol 2012 Mar;51(1):33-51. [doi: 10.1348/014466610X533768] [Medline: 22435845]

35. Taber JM, McQueen A, Simonovic N, Waters EA. Adapting a self-affirmation intervention for use in a mobile application for smokers. J Behav Med 2019 Dec;42(6):1050-1061. [doi: 10.1007/s10865-019-00028-1] [Medline: $\underline{30903442]}$

36. Memish KE, Schüz N, Frandsen M, Ferguson SG, Schüz B. Using self-affirmation to increase the effects of emotive health warnings on smoking: a randomized exploratory trial. Nicotine Tob Res 2017 Oct 01;19(10):1238-1242. [doi: 10.1093/ntr/ntw167] [Medline: 27613906]

37. Bommelé J, Schoenmakers TM, Kleinjan M, Peters GY, Dijkstra A, van de Mheen D. Targeting hardcore smokers: the effects of an online tailored intervention, based on motivational interviewing techniques. Br J Health Psychol 2017 Dec;22(3):644-660. [doi: 10.1111/bjhp.12256] [Medline: 28703470]

38. Epton T, Norman P, Dadzie A, Harris PR, Webb TL, Sheeran P, et al. A theory-based online health behaviour intervention for new university students (U@Uni): results from a randomised controlled trial. BMC Public Health 2014 Jun 05;14:563 [FREE Full text] [doi: 10.1186/1471-2458-14-563] [Medline: 24903620]

39. Dillard A, McCaul K, Magnan R. Why is such a smart person like you smoking? Using self-affirmation to reduce defensiveness to cigarette warning labels. J Appl Biobehav Res 2005;10(3):165-182. [doi:

10.1111/j.1751-9861.2005.tb00010.x]

40. Zhao X, Peterson EB, Kim W, Rolfe-Redding J. Effects of self-affirmation on daily versus occasional smokers' responses to graphic warning labels. Commun Res 2012 Nov 09;41(8):1137-1158. [doi: 10.1177/0093650212465433]

41. Harris PR, Griffin DW, Napper LE, Bond R, Schüz B, Stride C, et al. Individual differences in self-affirmation: distinguishing self-affirmation from positive self-regard. Self Identity 2018 Aug 21;18(6):589-630. [doi: 10.1080/15298868.2018.1504819]

42. Cornil Y, Chandon P. From fan to fat? Vicarious losing increases unhealthy eating, but self-affirmation is an effective remedy. Psychol Sci 2013 Oct;24(10):1936-1946. [doi: 10.1177/0956797613481232] [Medline: 23925307]

43. Toma CL, Hancock JT. Self-affirmation underlies Facebook use. Pers Soc Psychol Bull 2013 Mar;39(3):321-331. [doi: 10.1177/0146167212474694] [Medline: 23359086]

44. Ferrer RA, Taber JM, Klein WM, Harris PR, Lewis KL, Biesecker LG. The role of current affect, anticipated affect and spontaneous self-affirmation in decisions to receive self-threatening genetic risk information. Cogn Emot 2015;29(8):1456-1465 [FREE Full text] [doi: 10.1080/02699931.2014.985188] [Medline: 25482843] 
45. Taber JM, Howell JL, Emanuel AS, Klein WM, Ferrer RA, Harris PR. Associations of spontaneous self-affirmation with health care experiences and health information seeking in a national survey of US adults. Psychol Health 2016;31(3):292-309 [FREE Full text] [doi: 10.1080/08870446.2015.1085986] [Medline: 26315683]

46. Emanuel AS, Howell JL, Taber JM, Ferrer RA, Klein WM, Harris PR. Spontaneous self-affirmation is associated with psychological well-being: evidence from a US national adult survey sample. J Health Psychol 2018 Jan;23(1):95-102. [doi: 10.1177/1359105316643595] [Medline: 27160152]

47. Creswell JD, Lam S, Stanton AL, Taylor SE, Bower JE, Sherman DK. Does self-affirmation, cognitive processing, or discovery of meaning explain cancer-related health benefits of expressive writing? Pers Soc Psychol Bull 2007 Feb;33(2):238-250. [doi: 10.1177/0146167206294412] [Medline: 17259584]

48. Persoskie A, Ferrer RA, Taber JM, Klein WMP, Parascandola M, Harris PR. Smoke-free air laws and quit attempts: evidence for a moderating role of spontaneous self-affirmation. Soc Sci Med 2015 Sep;141:46-55. [doi:

10.1016/j.socscimed.2015.07.015] [Medline: 26246033]

49. Scheier MF, Carver CS, Bridges MW. Distinguishing optimism from neuroticism (and trait anxiety, self-mastery, and self-esteem): a reevaluation of the Life Orientation Test. J Pers Soc Psychol 1994 Dec;67(6):1063-1078. [doi: 10.1037//0022-3514.67.6.1063] [Medline: 7815302]

50. Monzani D, Steca P, Greco A, D'Addario M, Pancani L, Cappelletti E. Effective pursuit of personal goals: the fostering effect of dispositional optimism on goal commitment and goal progress. Pers Individ Dif 2015 Aug;82:203-214. [doi: 10.1016/j.paid.2015.03.019]

51. Segerstrom SC, Nes LS. When goals conflict but people prosper: the case of dispositional optimism. J Res Pers 2006 Oct;40(5):675-693 [FREE Full text] [doi: 10.1016/j.jrp.2005.08.001] [Medline: 17016545]

52. Lerner JS, Han S, Keltner D. Feelings and consumer decision making: extending the appraisal-tendency framework. J Consum Psychol 2007 Jul;17(3):181-187. [doi: 10.1016/s1057-7408(07)70027-x]

53. Lerner JS, Keltner D. Beyond valence: toward a model of emotion-specific influences on judgement and choice. Cogn Emot 2000 Jul;14(4):473-493. [doi: 10.1080/026999300402763]

54. Lerner JS, Keltner D. Fear, anger, and risk. J Pers Soc Psychol 2001 Jul;81(1):146-159. [doi: 10.1037//0022-3514.81.1.146] [Medline: 11474720$]$

55. Dorison CA, Wang K, Rees VW, Kawachi I, Ericson KMM, Lerner JS. Sadness, but not all negative emotions, heightens addictive substance use. Proc Natl Acad Sci U S A 2020 Jan 14;117(2):943-949 [FREE Full text] [doi: 10.1073/pnas.1909888116] [Medline: 31888990]

56. Lerner JS, Li Y, Weber EU. The financial costs of sadness. Psychol Sci 2012 Nov 13;24(1):72-79. [doi: 10.1177/0956797612450302]

57. Garg N, Lerner JS. Sadness and consumption. J Consum Psychol 2013 Jan;23(1):106-113. [doi: 10.1016/j.jcps.2012.05.009]

58. Cohen GL, Garcia J, Purdie-Vaughns V, Apfel N, Brzustoski P. Recursive processes in self-affirmation: intervening to close the minority achievement gap. Science 2009 Apr 17;324(5925):400-403 [FREE Full text] [doi:

10.1126/science.1170769] [Medline: 19372432]

59. Logel C, Cohen GL. The role of the self in physical health: testing the effect of a values-affirmation intervention on weight loss. Psychol Sci 2012 Jan 01;23(1):53-55. [doi: 10.1177/0956797611421936] [Medline: 22157517]

60. Goyer JP, Garcia J, Purdie-Vaughns V, Binning KR, Cook JE, Reeves SL, et al. Self-affirmation facilitates minority middle schoolers' progress along college trajectories. Proc Natl Acad Sci U S A 2017 Jul 18;114(29):7594-7599 [FREE Full text] [doi: 10.1073/pnas.1617923114] [Medline: 28630338]

61. Taber JM, Klein WM, Ferrer RA, Augustson E, Patrick H. A pilot test of self-affirmations to promote smoking cessation in a national smoking cessation text messaging program. JMIR Mhealth Uhealth 2016 Jun 08;4(2):e71 [FREE Full text] [doi: 10.2196/mhealth.5635] [Medline: 27278108]

62. Augustson E, Cole-Lewis H, Sanders A, Schwarz M, Geng Y, Coa K, et al. Analysing user-reported data for enhancement of SmokefreeTXT: a national text message smoking cessation intervention. Tob Control 2017 Nov;26(6):683-689. [doi: 10.1136/tobaccocontrol-2016-052945] [Medline: 27852892]

63. Heatherton TF, Kozlowski LT, Frecker RC, Fagerström KO. The Fagerström test for nicotine dependence: a revision of the Fagerström tolerance questionnaire. Br J Addict 1991 Sep;86(9):1119-1127. [doi: 10.1111/j.1360-0443.1991.tb01879.x] [Medline: 1932883]

64. DiClemente CC, Prochaska JO, Fairhurst SK, Velicer WF, Velasquez MM, Rossi JS. The process of smoking cessation: an analysis of precontemplation, contemplation, and preparation stages of change. J Consult Clin Psychol 1991 Apr;59(2):295-304. [doi: 10.1037//0022-006x.59.2.295] [Medline: 2030191]

65. Watson D, Clark LA, Tellegen A. Development and validation of brief measures of positive and negative affect: the PANAS scales. J Pers Soc Psychol 1988 Jun;54(6):1063-1070. [doi: 10.1037//0022-3514.54.6.1063] [Medline: $\underline{3397865]}$

66. Radler B. The Midlife in the United States (MIDUS) Series: a national longitudinal study of health and well-being. Open Health Data 2014;2(1):e3 [FREE Full text] [doi: 10.5334/ohd.ai] [Medline: 25558376]

67. Mroczek DK, Kolarz CM. The effect of age on positive and negative affect: a developmental perspective on happiness. J Pers Soc Psychol 1998 Nov;75(5):1333-1349. [doi: 10.1037//0022-3514.75.5.1333] [Medline: 9866191] 
68. Scheier MF, Carver CS. Optimism, coping, and health: assessment and implications of generalized outcome expectancies. Health Psychol 1985;4(3):219-247. [doi: 10.1037//0278-6133.4.3.219] [Medline: 4029106]

69. Reed M, Aspinwall L. Self-affirmation reduces biased processing of health-risk information. Motiv Emot 1998;22:99-132. [doi: 10.1023/A:1021463221281]

70. MCQueen A, Klein WM. Experimental manipulations of self-affirmation: a systematic review. Self Identity 2006 Oct;5(4):289-354. [doi: 10.1080/15298860600805325]

71. McEwen A. The "Not-a-Puff" rule. National Centre for Smoking Cessation and Training (NCSCT). 2013. URL: http:/ /www.ncsct.co.uk/usr/pub/not a puff rule.pdf [accessed 2020-12-22]

72. National Health Service. Stop Smoking Service. 2018. URL: https://www.nhs.uk/live-well/quit-smoking/ nhs-stop-smoking-services-help-you-quit/

73. Stata Statistical Software: Release 16. College Station, TX: StataCorp LLC; 2019. URL: https://www.stata.com/ [accessed 2020-12-22]

74. Mathieu E, McGeechan K, Barratt A, Herbert R. Internet-based randomized controlled trials: a systematic review. J Am Med Inform Assoc 2013 May 1;20(3):568-576 [FREE Full text] [doi: 10.1136/amiajnl-2012-001175] [Medline: 23065196]

75. Taber JM, Klein WMP, Ferrer RA, Lewis KL, Harris PR, Shepperd JA, et al. Information Avoidance Tendencies, Threat Management Resources, and Interest in Genetic Sequencing Feedback. Ann Behav Med 2015 Aug;49(4):616-621 [FREE Full text] [doi: 10.1007/s12160-014-9679-7] [Medline: 25582989]

76. Schneider S, Gadinger M, Fischer A. Does the effect go up in smoke? A randomized controlled trial of pictorial warnings on cigarette packaging. Patient Educ Couns 2012 Jan;86(1):77-83. [doi: 10.1016/j.pec.2011.03.005] [Medline: 21482060]

77. Taber JM, Klein WM, Ferrer RA, Kent EE, Harris PR. Optimism and spontaneous self-affirmation are associated with lower likelihood of cognitive impairment and greater positive affect among cancer survivors. Ann Behav Med 2016 Apr;50(2):198-209 [FREE Full text] [doi: 10.1007/s12160-015-9745-9] [Medline: 26497697]

78. Leventhal AM, Piper ME, Japuntich SJ, Baker TB, Cook JW. Anhedonia, depressed mood, and smoking cessation outcome. J Consult Clin Psychol 2014 Feb;82(1):122-129 [FREE Full text] [doi: 10.1037/a0035046] [Medline: 24219183]

\author{
Abbreviations \\ ANOVA: analysis of variance \\ OR: odds ratio \\ RCT: randomized controlled trial \\ SSAM: spontaneous self-affirmation measure
}

Edited by G Eysenbach; submitted 26.02.20; peer-reviewed by $S$ Walters, J Willoughby, A Moyer; comments to author 29.06.20;
revised version received 21.08.20; accepted 11.11.20; published 05.03.21
Please cite as:
Seaman EL, Robinson CD, Crane D, Taber JM, Ferrer RA, Harris PR, Klein WMP
Association of Spontaneous and Induced Self-Affirmation With Smoking Cessation in Users of a Mobile App: Randomized Controlled
Trial
J Med Internet Res 2021;23(3):e18433
URL: $\underline{\text { https://www.jmir.org/2021/3/e18433 }}$
doi: $10.2196 / 18433$
PMID: $\underline{3666561}$

CElizabeth L Seaman, Cendrine D Robinson, David Crane, Jennifer M Taber, Rebecca A Ferrer, Peter R Harris, William M P Klein. Originally published in the Journal of Medical Internet Research (http://www.jmir.org), 05.03.2021. This is an open-access article distributed under the terms of the Creative Commons Attribution License (https://creativecommons.org/licenses/by/4.0/), which permits unrestricted use, distribution, and reproduction in any medium, provided the original work, first published in the Journal of Medical Internet Research, is properly cited. The complete bibliographic information, a link to the original publication on http://www.jmir.org/, as well as this copyright and license information must be included. 